\title{
Getting to Know Guerilla Science Participants: Evaluating Unexpected and Unusual Science Encounters
}

\author{
A Report Prepared for the Simons Foundation
}

Prepared by:

Kari O'Connell

Brianna Keys

Martin Storksdieck

Center for Research on Lifelong STEM Learning

Oregon State University

254 Gilbert Hall

Corvallis, OR 97331

July 23,2018

Cite as:

O'Connell, K., Keys, B., \& Storksdieck, M. (2018): Getting to Know Guerilla Science Participants: Evaluating Unexpected and Unusual Science Encounters. Technical Report. Corvallis, OR: Oregon State University. 


\section{Table of Contents}

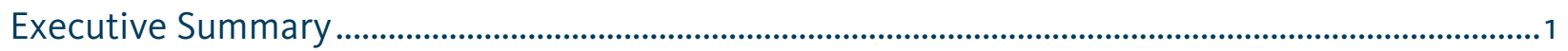

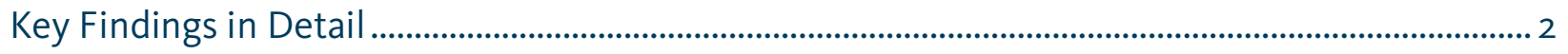

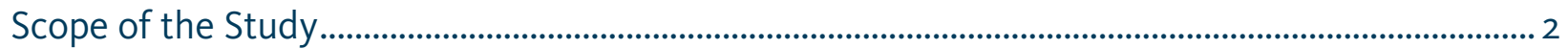

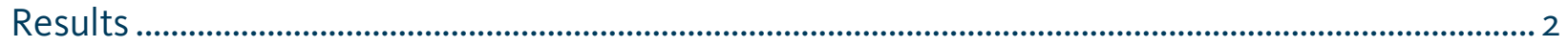

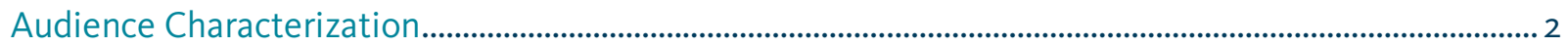

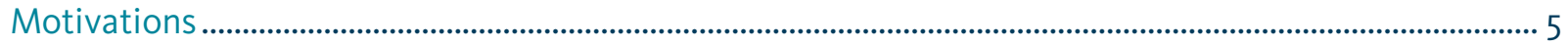

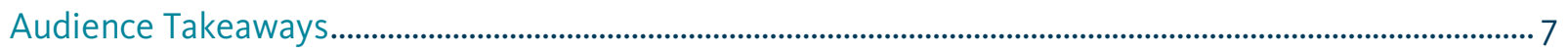

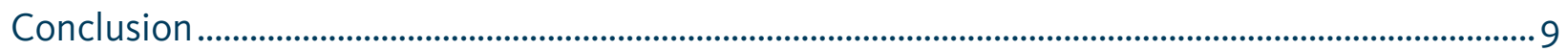

Concluding on Research Questions ................................................................................................................

Evaluation Development and Impact ............................................................................................................... 10

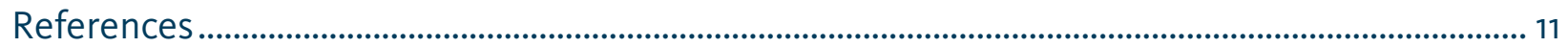

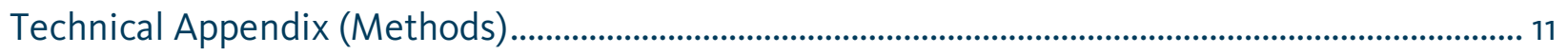

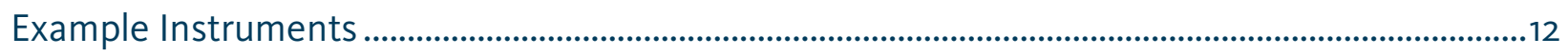




\section{Executive Summary}

Creative projects at the interface of science and art can be appealing to both science-interested and art-interested audiences. They therefore present a unique opportunity to connect with cultural and learning identities of a wide range of people, and to preach beyond the already-interested and scienceengaged "choir" that make up a significant proportion of science museum attendees and consumers of science media.

Guerilla Science develops live events that bring scientists into face-to-face contact with the public as part of imaginatively designed immersive story worlds, often co-designed with artists (e.g. sound artists, performance artists, food and experience designers and visual artists), that take place in the places and spaces where science is least expected, for example music and arts festivals, disused urban spaces, and nightclubs. Its primary target audience are young adults who do not see science as being for them. Since its inception in 2008, Guerilla Science has reached over 100,000 members of the public, worked with over 300 scientists and artists, and been featured in publications like The New Yorker, Guardian, $B B C$, and Vice.

The Center for Research on Lifelong STEM Learning at Oregon State University was invited by Guerilla Science to evaluate four events that Guerilla Science has produced in recent years that bring science into spaces that are part of the domain of popular culture and the arts: Sensory Speed Dating, Works on Water, Flavor Feast, and Sweet Shoppe. We use audience data gathered through surveys and interviews at these events to provide insights into two main research questions:

1. Who participates in the Guerilla Science events and what are their motivations for participation?

2. What did participants take away from their participation in Guerilla Science?

Our data reveal that through their carefully curated and artistically designed events, Guerilla Science attracts a wide variety of culturally interested and engaged people by sparking their curiosity. Guerilla Science participants, for the most part, expressed a high value and interest in science in general. This generic "appreciation" for science is reflective of what we know of the general population in the United States. However, the participants' highly positive attitudes toward science did not always translate into a strong social connection to science by knowing people who work in science-related fields or engaging with science by indicating that they participate in spare-time activities related to science. We label this segment of the population as "latently" interested in science in that they have positive attitudes toward science, but do not necessarily choose to engage with it. Guerilla Science events offer an important space for members of this "latently" interested public to engage as they may not otherwise choose to participate in more traditional science learning activities elsewhere. Following their experiences, participants generally expressed high levels of satisfaction and shared primary takeaways that were learning-related, noting gained knowledge, interesting facts, and better understanding of the topics addressed in the event.

These data ultimately suggest that Guerilla Science's mission to "revolutionize how people connect with science" coupled with their tagline to "spark curiosity, defy convention, and inspire wonder", their methods of creating immersive, artistic experiences, and their strategy of meeting people where they are in an effort to engage those beyond the science-engaged choir are being successful. 


\section{Key Findings in Detail}

- Guerilla Science participants are highly culturally engaged individuals who report an identity connection to a wide array of arts-, cultural-, and science-related topics. They also report a high preference for engaging in cultural and social experiences. When put in the context of one another, participants report engaging with art more so than science.

- By assessing participants' value of, interest in, connection to, and engagement in science, we find that Guerilla Science attracts a variety of people who range from those who are enthusiastic and highly engaged to those who express generic appreciation, but lack a real relationship with science. By engaging with those in the latter category, Guerilla Science offers a unique space to interact with science for those who might not otherwise experience it.

- Guerilla Science attracts participants by making them curious. Participants also reported being enticed by the type of event and joining friends who had wanted to come, motivations that reflect their general interests and activities as indicated above. At Sweet Shoppe, when asked if they came for the content or the format, participants selected both equally, indicating that both are important considerations for attracting Guerilla Science's target population. That is, the audience of Guerilla Science appreciates the blend between creative and artistic experiences and science content.

- Though the motivation to satisfy curiosity is primarily what brings participants through the door, the reported initial primary takeaways are learning-related. When asked what they were taking away from the event, many respondents referenced specific facts they discovered or new experiences that instilled new topic-related knowledge.

\section{Scope of the Study}

This evaluation project was dedicated to the examination of the following questions:

1. Who participates in the Guerilla Science events and what are their motivations for participation?

2. What did participants take away from their participation in Guerilla Science?

Data were gathered through short written questionnaires and "spot" interviews at four (4) events produced by Guerilla Science between November 2016 and December 2017: Sensory Speed Dating, Works on Water, Flavor Feast at Burning Man, and Sweet Shoppe.

\section{Results}

\section{Audience Characterization}

To understand how participants see themselves, we asked questions about their topics and activities of interest. When asked to share the topics that best describe them and the activities in which they most enjoy participating, science was chosen at a rate less often than other art- or culture-related topics and activities. For example, only $22 \%$ of participants at Sweet Shoppe included science museums when asked to pick their top three activities, while the top answers were wining and dining out and going to the movies, at $38 \%$ and $37 \%$, respectively (Figure 1). Similarly, when asked to select all of the topics that 
best described them from a collection of 10 options, science fell in the middle, with around $56 \%$ of respondents making the selection. For comparison, $67 \%$ said that music was included in their interests and on the lower end, only $28 \%$ of respondents included sports in their preferred topics of interest (Figure 2).

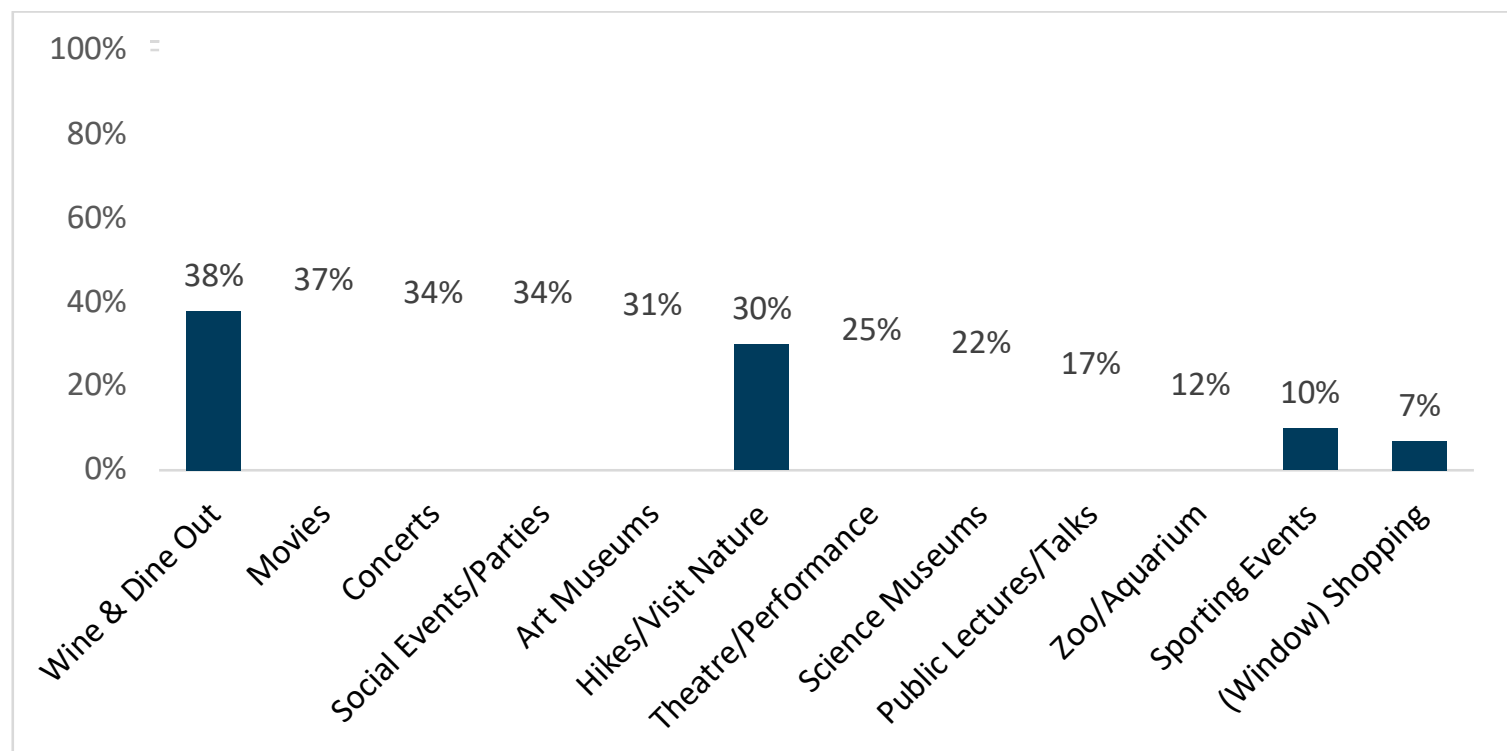

Figure 1. Please pick from the following list the three activities you most enjoy participating in (\% responding "yes") (n=256). Data collected from Sweet Shoppe in December, 2017.

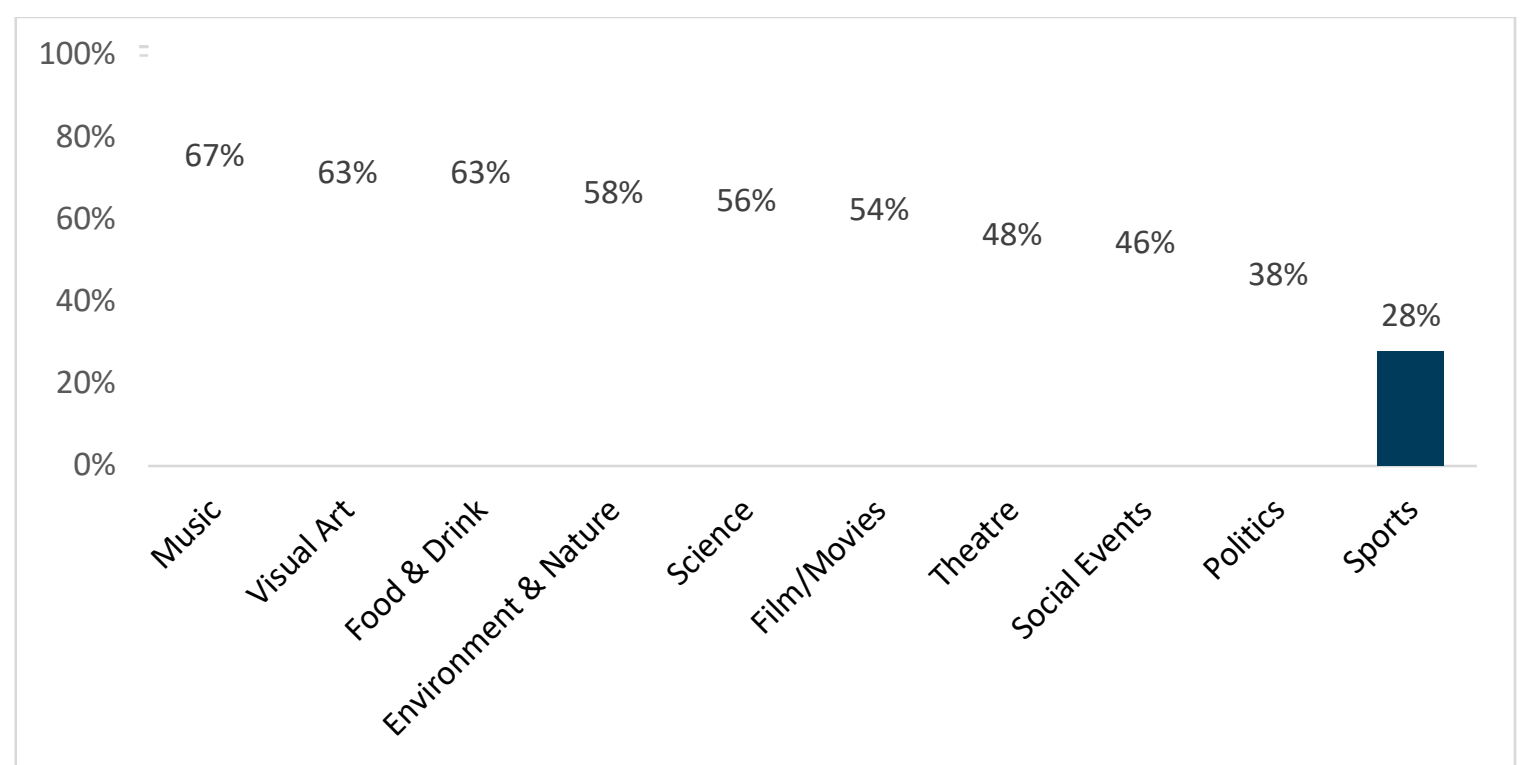

Figure 2. Please pick from the following list the topics that best describe you and your interests (Check all that apply) (\% responding "yes") ( $n=237)$. Data collected from Works on Water (June 2017) and Flavor Feast (August/September 2017).

Data from Works on Water, the theater event in Manhattan, also suggest that Guerilla Science attracts participants who are more interested in art than science, in contrast to national trends. For example, $91 \%$ of Works on Water participants reported that they visit art events, galleries, exhibits, or concerts at 
least once a year and $82 \%$ visit science museums, science centers, festivals, zoos, aquariums, botanical gardens, or planetariums at least once a year (Figure 3). This compares to national data that reports $58 \%$ of the adult population visiting some kind of informal science institution at least once a year versus 33\% who visit art museums once a year. National Science Board data (2018) indicates that these Guerilla Science participants may not only have a much higher interest in all things cultural, whether art- or science-related, but show much stronger relative participation levels in art versus science, with close to equal rates, than relative participation levels in the general public, where there is almost twice the level for science over art. The data become even more clear when we look at higher frequency visits that may hide behind aggregate annual data: $64 \%$ of Works on Water participants stated that they visit art events or institutions at least once a month compared to only $16 \%$ who visit informal science institutions once a month. These finer-grained data suggest that Guerilla Science attracts an audience that, on average, attends science-related activities far less frequently than those related to art, and therefore express a much stronger affinity for art than for science.

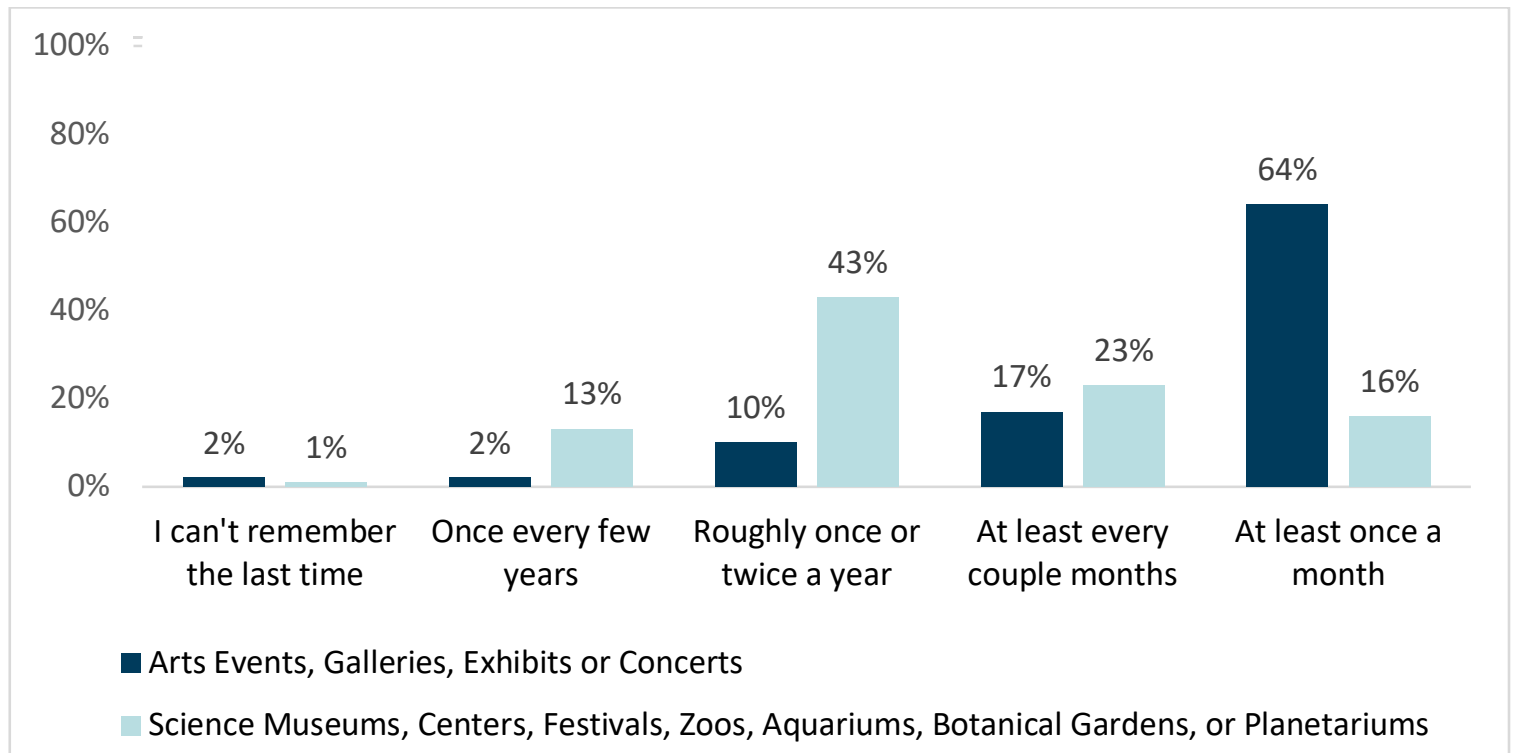

Figure 3. How many times would you say that you visit... (\% respondents) ( $n=111)$ Data collected from Works on Water in June 2017.

To further characterize the people who choose to engage with Guerilla Science, we examined their preexisting relationships with science. Overall, the US population of adults has a positive public perception of scientists, with $94 \%$ and $98 \%$, respectively agreeing that scientists work to help to solve problems and want to make life better for the average person (National Science Board, 2018). These data roughly compare to data we collected from Guerilla Science participants, $95 \%$ of whom agree or highly agree with the statement, "Science helps us solve problems to make the world a better place" (Figure 4). When asked about their "interest in new scientific discoveries", 84\% of the general US population reports being "moderately interested" or "very interested" (National Science Board, 2018). Though that measure is a narrower view that focuses solely on one aspect of science (i.e. scientific discoveries), this high level of interest in science was reflected in Guerilla Science participants, 94\% of whom reported "agreeing" or "highly agreeing" with a more general statement "I find topics related to 
science interesting." However, positive attitudes towards and interest in science do not necessarily strongly translate to experiencing or engaging with science in everyday life. Thus, we measured the shift from the passive relationship to science into a more active relationship by assessing the statements "I know a lot of people who study science or work in a science- or research-related field" and "In my spare time, I [sometimes like to] engage in science-related activities".

When asked to rate their agreement with these four statements related to value, interest, connection to, and engagement with science, participants at Works on Water, Flavor Feast and Sweet Shoppe indicated lower agreement with statements that reflected a closer relationship to science (Figure 4). For example, $86 \%$ of the respondents highly agreed with the statement, "Science helps us solve problems to make the world a better place," but only $35 \%$ of the respondents highly agreed with the statement, "in my spare time, I (sometimes like to) engage in science-related activities". We label this segment of the population as "latently" interested in science in that they have positive attitudes toward science, but do not necessarily choose to engage with science. Guerilla Science events offer an important space for members of this "latently" interested public to engage in science.

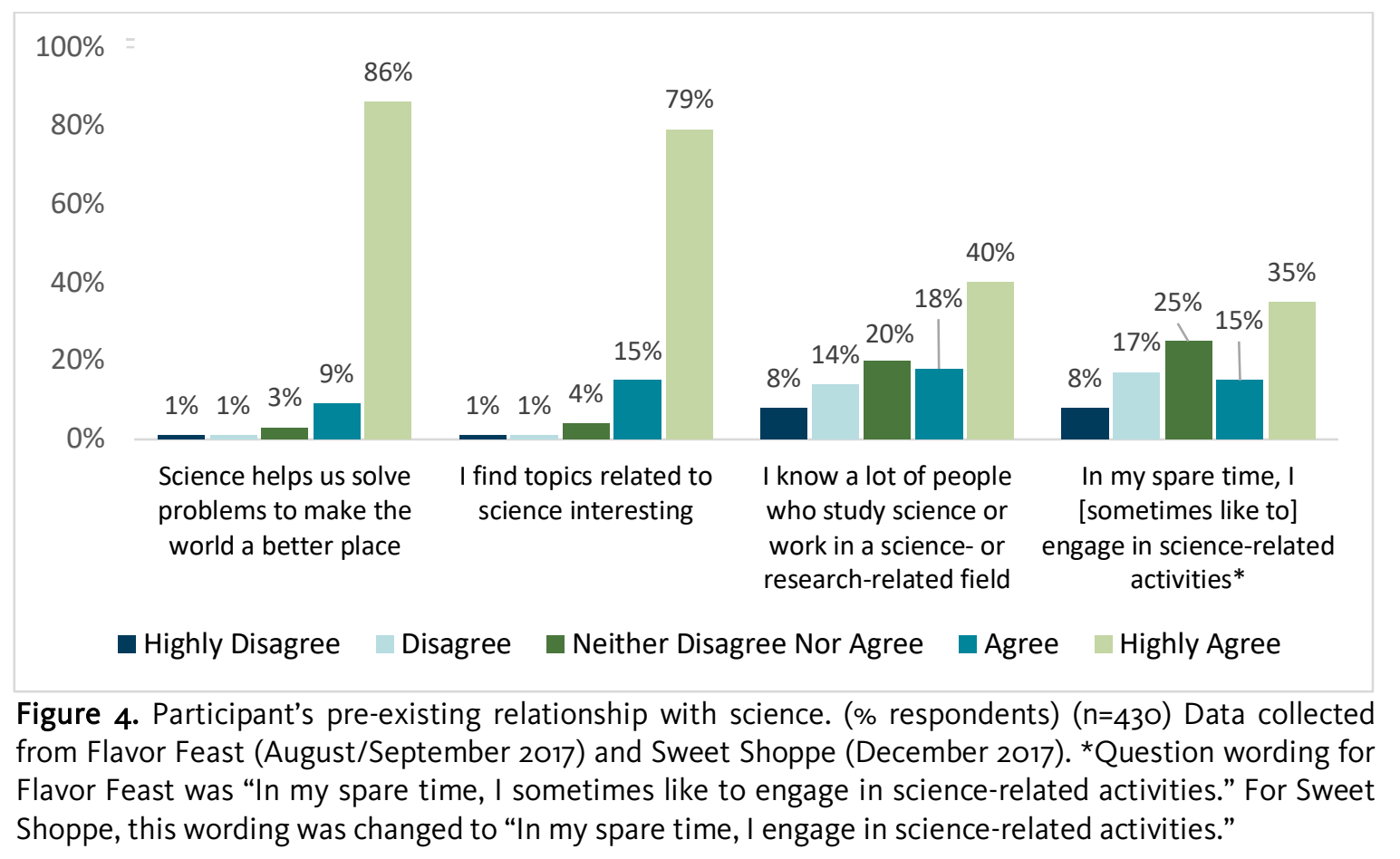

\section{Motivations}

When asked why they chose to come to the Guerilla Science events, respondents revealed an array of motivations; however, our data indicate that people who attend Guerilla Science events are most motivated by curiosity and the promise of a memorable experience. Closed-ended feedback from Works on Water and Flavor Feast indicated that respondent motivation was overwhelmingly curiosity, as expressed by $65 \%$ of respondents. The second and third most popular responses were liking to attend events like the current event and tagging along with friends, at $36 \%$ and $35 \%$, respectively (Figure 5). 


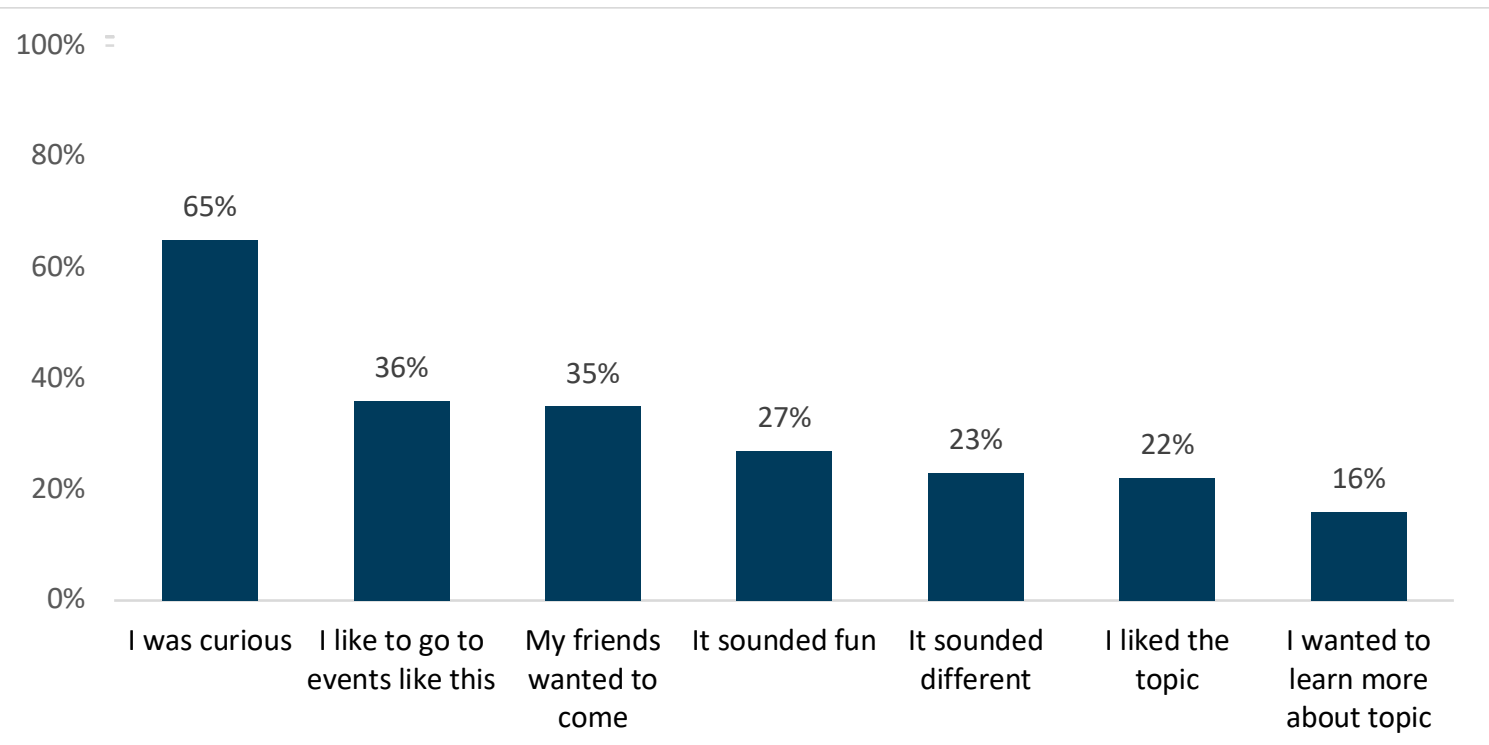

Figure 5. Why did you decide to come to [this event]? (Check all that apply) (\% responding "Yes") ( $n=283$ ) Data collected from Works on Water (June 2017) and Flavor Feast (August/September 2017).

Interviewees who attended Works on Water largely responded to an open-ended question that they attended because they knew the production company, the theater, or people involved in the play (71\%) (Figure 6). Nearly half (45\%) indicated that they were motivated by an interest in water. Twenty percent said they came because they enjoy theater and an additional 17\% said that they came to attend with someone else. These data reflect the social nature of the theater scene in Manhattan and the general interests of Guerilla Science participants to engage in art-related activities.

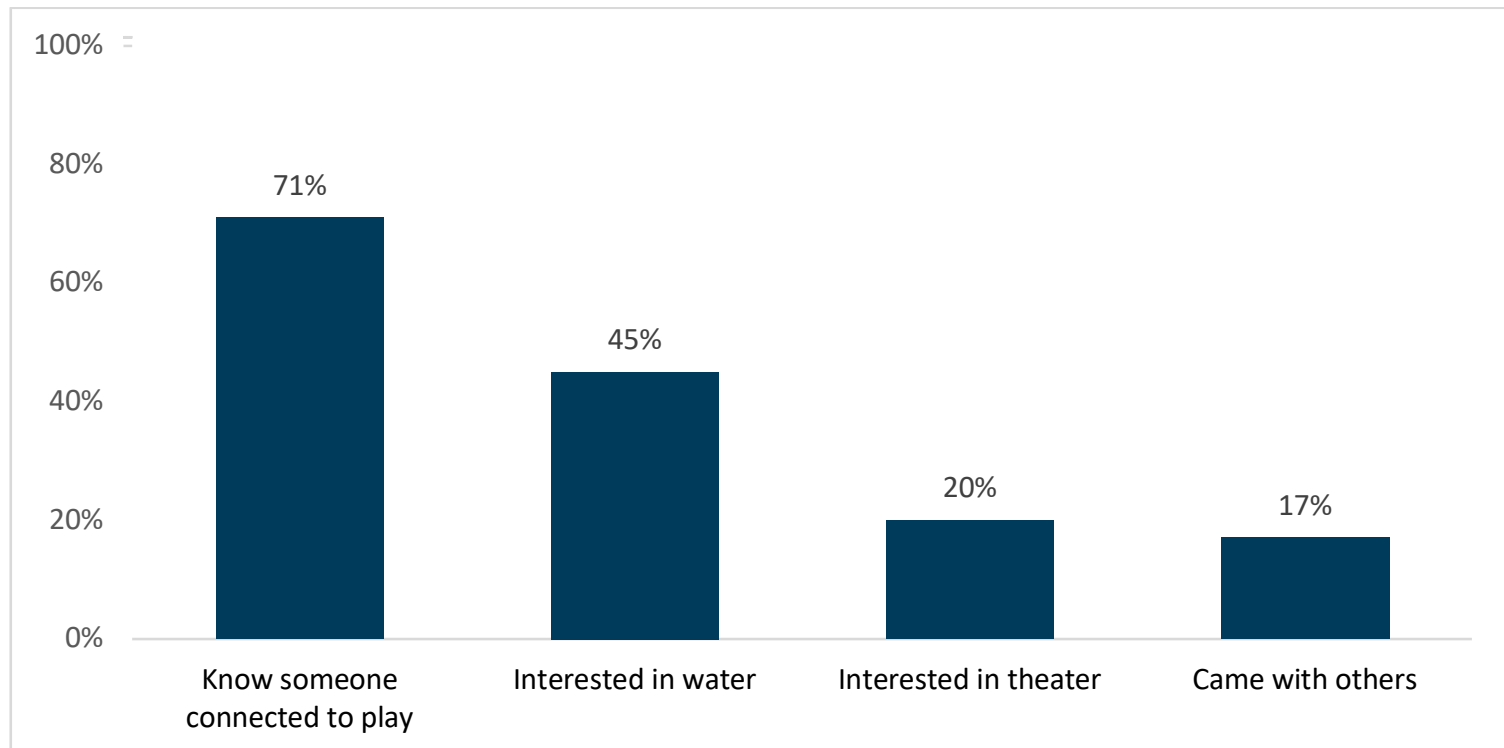

Figure 6. Why did you decide to come to Works on Water today? (\% respondents) ( $n=65)$ Data collected June 2017. Open-ended answers were coded and then frequencies of the codes were calculated. 
Attendants to Sweet Shoppe indicated that they were equally attracted by the format of the event as compared to the content of the event (62\% and 58\%, respectively) (Figure 7). Responding to what they most wanted to get out of attending by selecting all options that were applicable, only slightly more than one-third $(38 \%)$ said they had originally wanted to learn something, almost half $(46 \%)$ said that they had wanted to enjoy themselves, and nearly three-quarters $(71 \%)$ noted that they wanted to experience something new. These data highlight that both the format and content are important for Guerilla Science's participants, indicating that they chose to participate because of the presentation of the experience, i.e. the artistic and immersive event, as well as the promise to further engage with the topic at hand. In other words, Guerilla Science might not be as successful without their brand of engaging cultural experiences that are interwoven with relatable scientific topics.

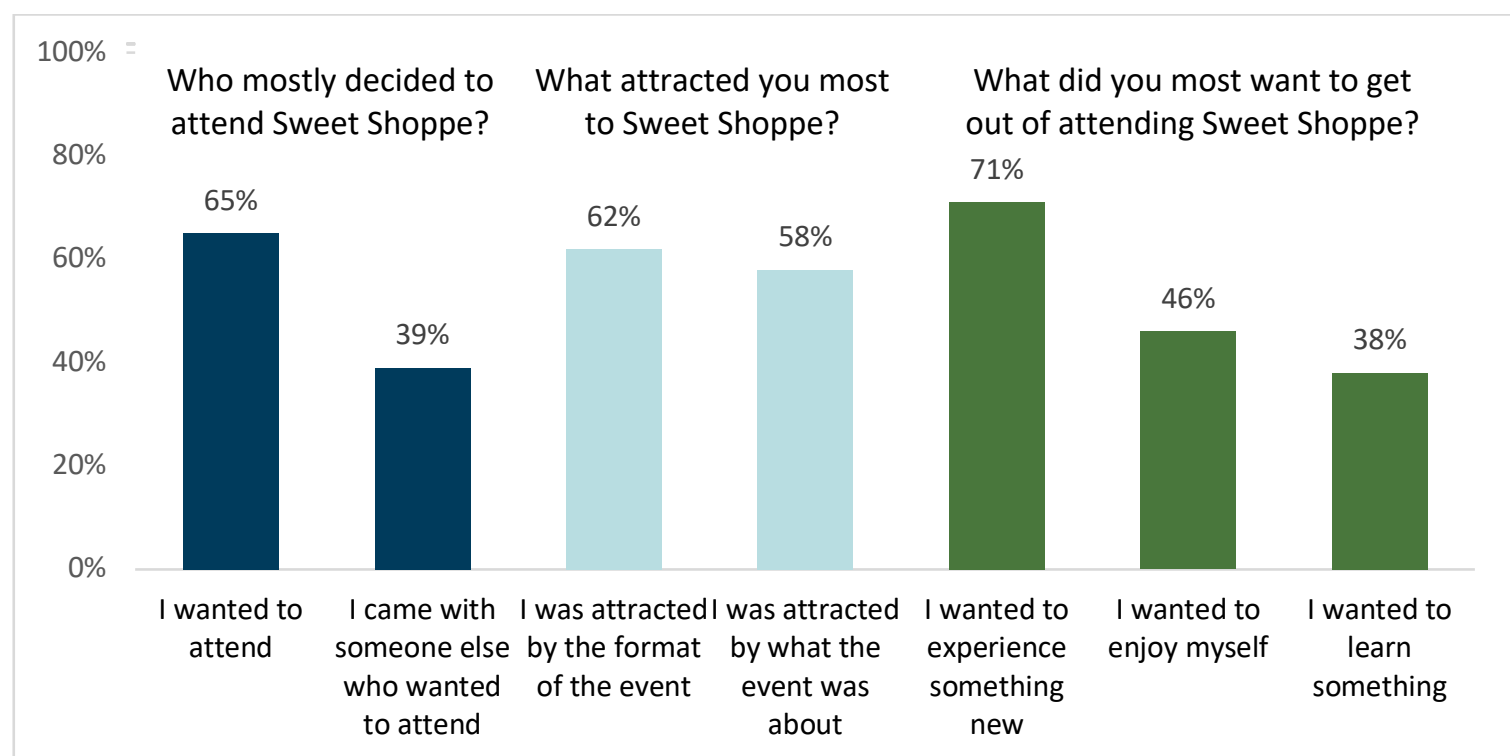

Figure 7. What brought you here? (Check all that apply) (\% responding "Yes") ( $\mathrm{n}=250)$ Data collected from Sweet Shoppe in December 2017.

\section{Audience Takeaways}

Our data show that even though attendees to Guerilla Science events do not necessarily initially decide to take part in the events to learn, their immediate primary takeaways are learning-related. Most of the respondents' comments referenced specific facts they discovered or new experiences that instilled new topic-related knowledge.

Respondents at Works on Water, Flavor Feast, and Sweet Shoppe were all asked the open-ended question "What did you take away from participating in this event?" (Figure 8). The majority of respondents made topical or factual references and indicated that they had learned something through their experience (43\% of WoW respondents, 59\% of Flavor Feast respondents, and $61 \%$ of Sweet Shoppe respondents). Examples include discovering the existence and effects of miracle berries and gymnema tea, which both block different receptors on taste buds, the ubiquitous nature of sugar and water, and the potential future experiences that loom with climate change and how our daily actions impact it. 
In addition to noting knowledge gain, the next largest type of takeaways were social or personal benefits such as an "amazing experience", "fun science event", and "an appreciation of the human connection with water" with $21 \%$ of respondents reporting. The third largest takeaway, by $12 \%$ of participants, was an increased recognition of the value or presence of science in general or the event subject (i.e. water, sugar) in our lives and the influence it has on us.

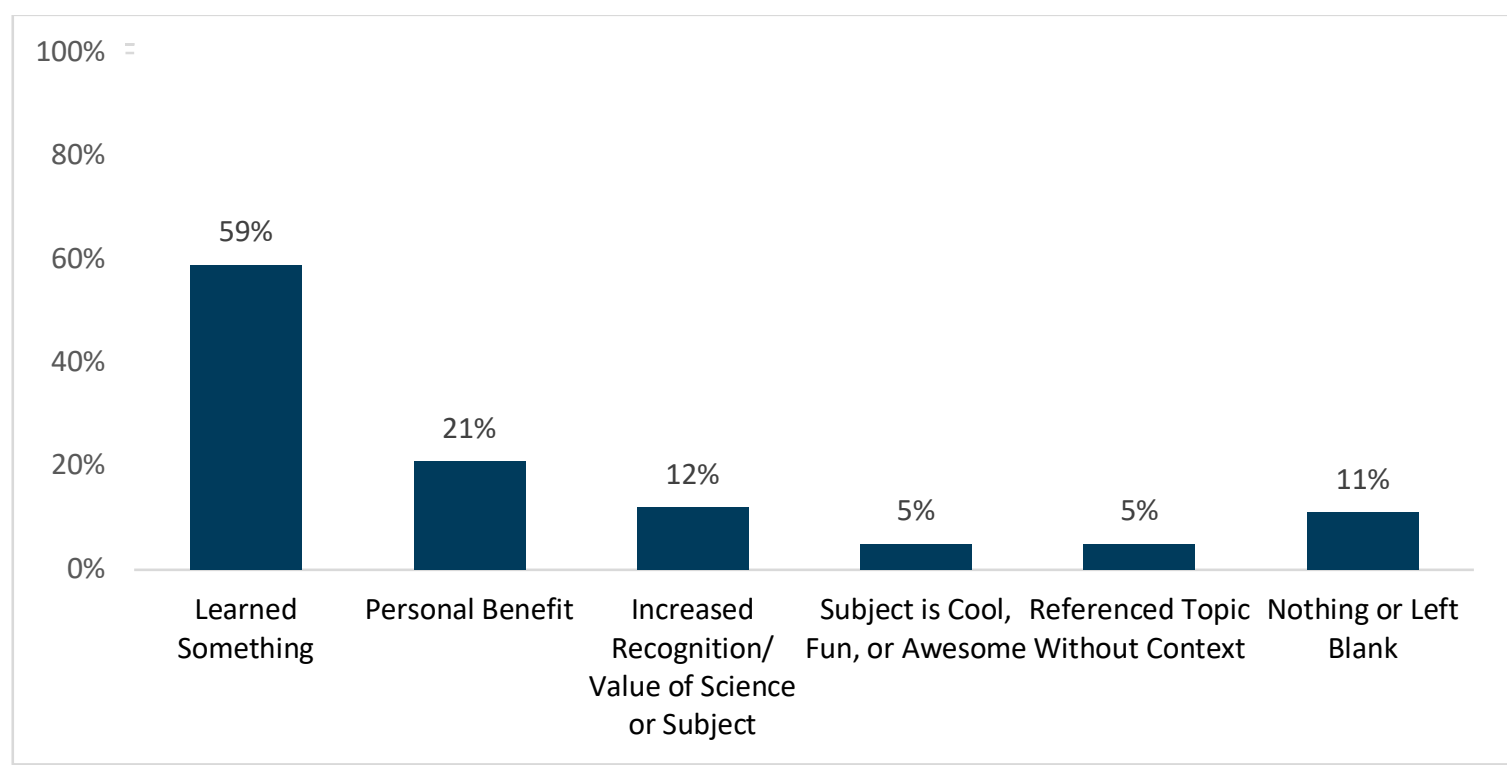

Figure 8. What did you take away from participating in this event? $(n=578)$ Data collected from Works on Water (June 2017), Flavor Feast (August/September 2017), and Sweet Shoppe (December 2017). Openended answers were coded and then frequencies of the codes were calculated.

Overall, participants reported positive experiences with Guerilla Science events. To measure satisfaction, participants at Works on Water were asked to rate their agreement on a scale from 1 to 10 on three statements: "I would recommend this event to a friend.", "I would attend/take part in an event like this again.", and "I am satisfied with this event.". The average of these three statements creates a Promoter rating, ranging from 1 to 10 . Individuals who have an average of 9 or 10 are considered "Promoters": they had such a positive experience that they will tell others about it and actively recruit others to engage. Those with scores of 7 or 8 are considered "Passive": they were satisfied with their experience, but will not become evangelists. Finally, those with an average score of 6 and below are considered "Detractors": these individuals were unsatisfied with their experience and will share that dissatisfaction with others. It is never expected that there will be zero Detractors who walk away from engaging with an organization; the goal is simply to maximize the number of Promoters one has and successful organizations will have more Promoters than they have Detractors. Works on Water participants reported an average Promoter score of 8 and overall there were $44 \%$ Promoters and $22 \%$ Detractors (Figure 8). Works on Water was the only event where we have collected data from these questions so far. 


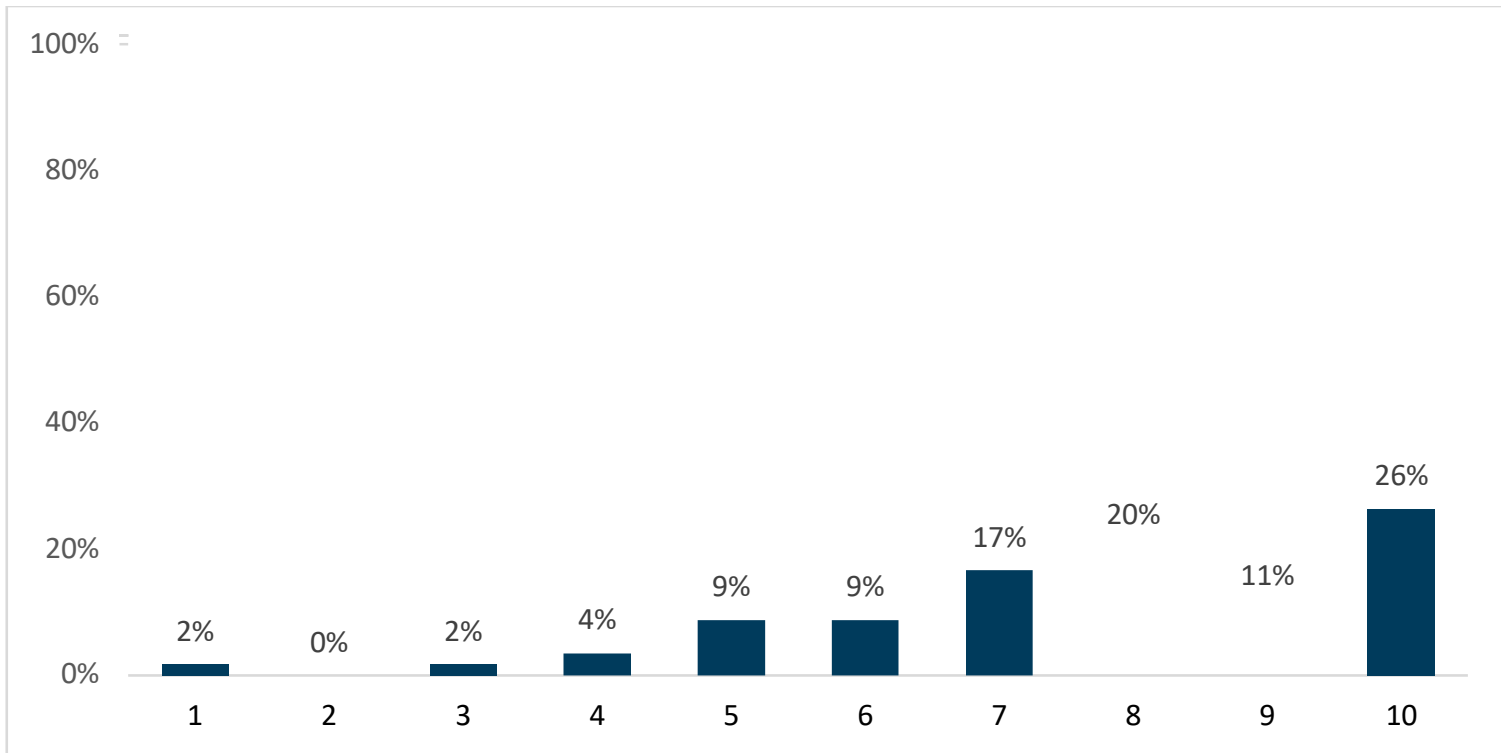

Figure 8. Works on Water Average Promoter Scores. Scores were calculated based on the average response to three questions: "I would recommend this event to a friend", "I would attend/take part in an event like this again", and "I am satisfied with this event". Data collected June 2017. ( $n=113)$

\section{Conclusion}

\section{Concluding on Research Questions}

Our data was able to provide insights into two main research questions about who and why people participate in Guerilla Science and what they take away from their participation.

Guerilla Science participants appear to be highly culturally-interested individuals, reporting high levels of interest in and engagement with a wide variety of cultural topics and activities. However, they report favoring art-related experiences more so than those related to science.

Guerilla Science participants also seem to have high value for and general interest in science, which aligns with what we know of the general population of the US. However, that value and interest does not always translate to connection to and engagement with science. Ultimately, our data show that Guerilla Science engages a variety of people with different relationships to science, from those who are highly interested and engaged, to those who are interested, but not engaged. This latter group, those we define as "latently" interested is an important group to note, as Guerilla Science may give them space to interact with science when they otherwise might not. This is especially important given Guerilla Science's mission of reaching people where they are at, beyond the so-called "science-engaged choir".

Guerilla Science attracts these individuals by tickling their curiosity. Interestingly, though the desire to learn more was the least popular motivation for initially deciding to engage with Guerilla Science, a majority of respondents reported that their initial takeaways were factual tidbits, topical enlightenment, and a better understanding of the human interaction with the subject at hand. These motivations align with Guerilla Science's mission to spark curiosity and show that their methods of initial interaction with people and their design of artistic, culturally-based events and experiences interwoven with scientific ideas are appropriately designed to achieve that goal. 


\section{Evaluation Development and Impact}

Given Guerilla Science's mission of bringing science into non-traditional places and spaces to interact with those who do not generally engage with science, a key part of our evaluation efforts was focused on learning about the participants' identities. Our initial efforts to understand the participants and the impact of these interactions gave light to more nuanced identities than was initially anticipated. For example, given the extremely high levels of general appreciation for science across all aspects of society, "appreciation" or "value" questions turned out not to be good discriminators for segmenting Guerilla Science audiences. Further, the unique contexts in which Guerilla Science events often take place and their carefully curated designs required considerations around adapting instruments and methods in order to integrate into the experience in a way that did not jar the participants from their immersion. Thus, we used each successive event to develop and refine a set of instruments and approaches to data collection from which we and others can pull as necessary, depending on the context.

Starting with Sensory Speed Dating, we included a core set of questions about the participants' interests, engagement with and social connection to science, but revised these over time, based on the data we collected, as well as the venue and location. These changes were primarily made to address the more nuanced categorization of attendees that we discovered was possible as the amount of data we collected increased. Over time with these events, we also revised our data collection about engagement with science from more "interest" questions to more targeted questions about "action" and choices related to engaging in science activities. In the future, we will include questions that will allow us to make direct comparisons to U.S. national data about attendance to informal science institutions.

We also included a reflective aspect of the study to consider the tools and approaches that we can use to examine these questions in a festival setting. The evaluation efforts undertaken to assess the reach and impact of Guerilla Science events funded from the Simons Foundation were also used to explore and inform the research and evaluation of the National Science Foundation-funded project, "Guerilla Science: STEM at Music and Art Festivals." We will pull key findings from the data collection to inform development of a handbook for others to use in designing similar scientific cultural experiences. 


\section{References}

National Science Board. 2018. Science and Engineering Indicators 2018. NSB-2018-1. Alexandria, VA: National Science Foundation. Available at https://www.nsf.gov/statistics/indicators/.

\section{Technical Appendix (Methods)}

The evaluations were comprised of spot entry and exit interviews, paper surveys administered immediately post event, and follow up online surveys for participants at the Guerilla Science events. Additionally, the evaluation at successive events supported the iterative development of tools and approaches that can be used in a wide variety of settings. In this report, we presented results from the following Guerilla Science events. Note that because we were exploring tools and approaches for data collection, we adjusted questions for several of the events. Sensory Speed Dating served as a pilot test of the online survey and evaluation questions. Due to the nature of the pilot, coupled with a relatively low participation rate, we are not reporting those results in this report.

\begin{tabular}{|c|c|c|c|}
\hline Event & Date & $\begin{array}{c}\text { Number of Evaluation } \\
\text { Participants }\end{array}$ & Evaluation Methods \\
\hline $\begin{array}{l}\text { Sensory Speed Dating } \\
\text { (New York City, NY) }\end{array}$ & November 17, 2016 & 41 & $\begin{array}{c}\text { Online Follow-Up Survey } \\
\text { (Pilot Test) }\end{array}$ \\
\hline $\begin{array}{l}\text { Works on Water (New } \\
\text { York City, NY) }\end{array}$ & June 5-30, 2017 & 184 & $\begin{array}{l}\text { Feedback Forms, Spot } \\
\text { Entry \& Exit Interviews, } \\
\text { Online Follow-Up Survey }\end{array}$ \\
\hline $\begin{array}{l}\text { Flavor Feast at Burning } \\
\text { Man (Black Rock City, NV) }\end{array}$ & $\begin{array}{c}\text { August } 27 \text { - September } \\
4,2017\end{array}$ & 168 & Feedback Forms \\
\hline $\begin{array}{l}\text { Sweet Shoppe (New York } \\
\text { City, NY) }\end{array}$ & December 1-3, 2017 & 274 & Feedback Forms \\
\hline
\end{tabular}

Total:

667

We asked the following kinds of questions in the evaluation.

To characterize the audience that participates in Guerilla Science events, we asked about:

- Science Interest, Attitude, and Engagement Likert scale questions

- Visits to art events/museums and informal science institutions (Works on Water)

- Age (Works on Water)

- Gender (Works on Water)

- Topics of interest

To understand the motivations of the audience, we asked about:

- Motivation for attending

- Who made the decision to attend (Sweet Shoppe)

To investigate audience takeaways, we asked about:

- What was most fascinating, interesting or enjoyable about the event (Works on Water)

- Descriptions of the event (close-ended) (Works on Water)

To characterize overall satisfaction with the event: 
- Net promoter score questions (Works on Water)

\section{Example Instruments}

Below are the instruments that we used for Works on Water, including the paper feedback form and the entry and exit spot interview, as an example of the questions asked of participants. Note that we made slight changes in the instruments depending on the context of the event and that most notably, we added Likert scale questions about science interest and engagement for Flavor Feast and Sweet Shoppe. See Figure 1 for the exact wording of those items. 
Thank you for helping us by sharing your thoughts about this event.

1. What motivated you to attend this event? [check all that apply]

$\square$ I was curious My friends wanted to come

$\square$ It sounded different

It sounded fun

$\square \quad$ I like to go to theatre

$\square$ I liked the topic

I wanted to learn more about the topic

2. Please rate how much you agree with the following statements on a scale from 1 (highly disagree) to 10 (highly agree).

I would recommend this event to a friend.

(1)
(2)
(3)

I would attend/take part in an event like this again.

(1) I am satisfied with this event.

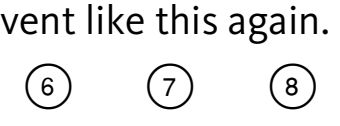

$$
\text { I } 12
$$

3. What was most fascinating, interesting or enjoyable about the event?

4. What did you take away from this event?

5. How would you describe the event today? [check all that apply]

$\begin{array}{llll}\square \text { Thought-provoking } & \square \text { Sociable } & \square \text { Confusing } \\ \square \text { Intimidating } & \square \text { Interactive } & \square \text { Informative } \\ \square \text { Boring } & \square \text { Relevant } & \square \text { Inspiring }\end{array}$

Please flip over to backside. $\rightarrow$
6. How many times would you say that you visit arts events, galleries, exhibits, or concerts?

At least once a month
At least every couple months $\bigcirc$ I can't remember the last time
Roughly once or twice a year

7. How many times would you say that you visit science museums, science centers, science festivals, zoos, aquariums, botanical gardens, or planetariums?

At least once a month $\bigcirc$ Once every few years

$\bigcirc$ At least every couple months $\bigcirc$ I can't remember the last time

Roughly once or twice a year

8. How old are you?

9. I would describe myself as:

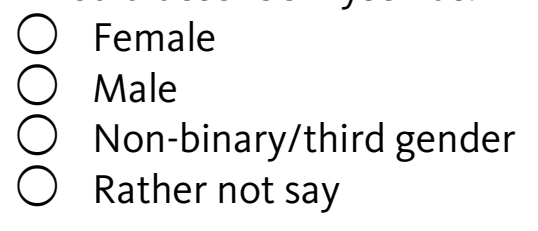

Thank you again for your time and giving us your valued feedback. 


\section{Entry Spot Interview}

1. Why did you decide to come tonight?

2. What do you expect to experience tonight?

3. [Hand respondent clipboard] Please pick from the following statements those that best describe you and your interests. You can choose as many as you'd like:

\begin{tabular}{|l|r|}
\hline$\square$ Music & $\square$ Film/movies \\
\hline$\square$ Art & $\square$ Environment and nature \\
\hline$\square$ Food and drink & $\square$ Theatre \\
\hline$\square$ Social events & $\square$ Sports \\
\hline$\square$ Science & $\square$ Politics \\
\hline
\end{tabular}

4. We will be contacting people for follow-up feedback. Could I get your email?

5. We're going to be talking to people again after the event tonight, is it okay if we talk to you again? [If yes] Great, can I get your first name?

Thank you for your time and enjoy the show! 


\section{Exit Spot Interview}

Ask if they spoke to someone else before the event. If they did, ask for their first name.

1. What did you take away from the event?

2. If there was one thing that could make the event more enjoyable, what would it be?

3. [If respondent did an entry interview, skip to the end and thank them for taking the time to answer your questions.]

4. [Hand respondent clipboard] Please pick from the following statements those that best describe you and your interests. You can choose as many as you'd like:

\begin{tabular}{|c|c|}
\hline$\square$ Music & $\square$ Film/movies \\
\hline$\square$ Art & $\square$ Environment and nature \\
\hline$\square$ Food and drink & $\square$ Theatre \\
\hline$\square$ Social events & $\square$ Sports \\
\hline$\square$ Science & $\square$ Politics \\
\hline
\end{tabular}

5. [If the respondent did not do an entry interview] We will be contacting people for follow-up feedback. Could I get your email?

Thank you for your time and have a great evening! 